\title{
Erratum to: What value is the CINAHL database when searching for systematic reviews of qualitative studies?
}

Kath Wright ${ }^{*}$, Su Golder ${ }^{2}$ and Kate Lewis-Light ${ }^{1}$

\section{Erratum}

After publication of [1] it came to the authors' attention that three percentage (\%) symbols were missed upon publication of their manuscript. The incorrect statement present in the Abstract and Results is "The median number of unique studies was 9.09; while the range had a lowest value of 5.0 to the highest value of 33.0". The correct statement is "The median \% of unique studies was $9.09 \%$; while the range had a lowest value of $5.0 \%$ to the highest value of $33.0 \%$ ". This has been updated in the original article.

\section{Author details}

${ }^{1}$ Centre for Reviews \& Dissemination, University of York, York, UK.

${ }^{2}$ Department of Health Sciences, University of York, York, UK.

Published online: 20 November 2015

\section{References}

1. Wright K, Golder S, Lewis-Light K. What value is the CINAHL database when searching for systematic reviews of qualitative studies? Systematic Reviews. 2015;4:104.

\footnotetext{
* Correspondence: kath.wright@york.ac.uk

${ }^{1}$ Centre for Reviews \& Dissemination, University of York, York, UK
}

Submit your next manuscript to BioMed Central and take full advantage of:

- Convenient online submission

- Thorough peer review

- No space constraints or color figure charges

- Immediate publication on acceptance

- Inclusion in PubMed, CAS, Scopus and Google Scholar

- Research which is freely available for redistribution 